\title{
FONTES DE NITROGÊNIO APLICADA EM COBERTURA NAS CULTURAS DO TRIGO E DA CEVADA
}

Godofredo Cesar Vitti ${ }^{*}$, Thiago Augusto de Moura ${ }^{2}$, Maria Regina Meirelles Faria ${ }^{3}$, Pedro Henrique Cerqueira $\mathrm{Luz}^{4}$

\footnotetext{
${ }^{1}$ USP/ESALQ - Depto. de Ciencia do Solo, C.P. 9 - CEP 13418 - 900 - Piracicaba, SP

${ }^{2}$ Aluno de Mestrado - Bolsista CAPES

${ }^{3}$ Eng. Agrônoma

${ }^{4}$ USP/FZEA - Depto de Agricultura, CEP 13630-000 - Pirassununga, SP

"E-mail para correspondência: gcvitti@esalq.usp.br
}

\section{RESUMO}

Dentre os macronutrientes primários nobres, o Nitrogênio $(\mathrm{N})$ é o mais utilizado, mais extraído pelas culturas, sendo também o de obtenção mais cara e o mais sujeito a lixiviação, devendo ser utilizado adequadamente. Dentre as fontes de N, a uréia apresenta custo mais barato, porem apresenta o problema de perdas por volatilização da amônia.Dentro desse contexto é importante o estudo de fontes alternativas viáveis do ponto de vista econômico e agronômico.Diante disso, objetivou-se comparar os efeitos da adubação de cobertura da uréia com cloreto de amônio (CA) nas culturas do trigo e da cevada. $\mathrm{O}$ experimento foi instalado no delineamento inteiramente casualizado para ambas culturas, contendo 7 tratamentos, 4 repetições e dois tipos de solo para a cultura do trigo, conforme segue: T1. controle $(0 \mathrm{~kg} / \mathrm{ha} \mathrm{N})$; T2. CA $(20 \mathrm{~kg} / \mathrm{ha} \mathrm{N}) ; \mathrm{T} 3$. CA $(40 \mathrm{~kg} / \mathrm{ha} \mathrm{N}) ; \mathrm{T} 4$. CA $(80 \mathrm{~kg} / \mathrm{ha} \mathrm{N}) ; \mathrm{T} 5$. Uréia $(20 \mathrm{~kg} / \mathrm{ha} \mathrm{N}) ; \mathrm{T} 6$. Uréia $(40 \mathrm{~kg} / \mathrm{ha} \mathrm{N}) ; \mathrm{T} 7$. Uréia $(80 \mathrm{~kg} / \mathrm{ha} \mathrm{N})$. O mesmo delineamento foi repetido para a cultura da cevada, somente em solo arenoso. Avaliaram-se os teores de $\mathrm{N}$ na folha no final do florescimento, inicio do enchimento de grãos, bem como, a estimativa de produtividade de grãos e teor de proteína bruta. Em todas avaliações as duas fontes não apresentaram diferenças significativas, mostrando que o cloreto de amônio pode ser fonte eficiente no fornecimento de nitrogênio à planta.

Palavras-chave: nitrogênio, fertilizantes, adubação, trigo, cevada

\section{NITROGEN SOURCES APPLIED ON COVERAGE ON WHEAT AND BARLEY CROPS}

\begin{abstract}
Among the primary macronutrients, the nitrogen $(\mathrm{N})$ is the most widely used one, the most extracted by the crops, and also the most expensive and the most prone to leaching and should be properly used. Among the sources of $\mathrm{N}$, the urea is cheaper, but presents the problem of loss by volatilization of ammonium. This is the reason why it is important to study alternative sources of economic and agricultural viability. This paper compares the effects of the coverage of urea fertilizer with ammonium chloride (AC) on wheat and barley crops. The experiment was conducted in a randomized design for both crops, containing 7 treatments, 4 replications and two types of soil for the cultivation of wheat, as follows: T1. Control $(0 \mathrm{~kg} / \mathrm{ha} \mathrm{N}), \mathrm{T} 2$. CA $(20 \mathrm{~kg} / \mathrm{ha}$ $\mathrm{N})$, T3. CA (40kg/ha N), T4. CA $(80 \mathrm{~kg} / \mathrm{ha} \mathrm{N})$; T5. Urea $(20 \mathrm{~kg} / \mathrm{ha} \mathrm{N})$, T6. Urea $(40 \mathrm{~kg} / \mathrm{ha} \mathrm{N})$, T7.
\end{abstract}


Urea $(80 \mathrm{~kg} / \mathrm{ha} \mathrm{N})$. The same design was repeated for the cultivation of barley, but only to in sandy soil. We evaluated the levels of $\mathrm{N}$ in the leaves at the end of the flowering period, at the beginning of grain filling, and also estimated grain yield and crude protein content. No significant differences were observed concerning the two sources, thus indicating that the ammonium chloride can be an efficient source of nitrogen for the plant.

Key words: nitrogen, fertilizer, wheat, barley

\section{INTRODUÇÃO}

Por ser exigido em grandes quantidades pelas culturas e por apresentar elevado custo de obtenção, o N, junto com o fósforo $(\mathrm{P})$ e o potássio $(\mathrm{K})$, é denominado macronutriente primário ou nobre. Entretanto, o custo de obtenção do $\mathrm{N}$ é praticamente cinco vezes maior do que o custo de obtenção de K (Vitti \& Heirinchs, 2007). Para sua obtenção a indústria de fertilizantes emprega como matérias-primas no processo, além do $\mathrm{N}_{2}$ atmosférico, o hidrogênio $\left(\mathrm{H}_{2}\right)$, obtido do gás natural, do gás residual de refinaria ou de derivados de petróleo como a nafta e o resíduo asfáltico para a produção de amônia $\left(\mathrm{NH}_{3}\right)$, produto primário da tecnologia, que será empregado na fabricação das várias fontes de fertilizantes nitrogenados. O elevado custo energético para a produção do fertilizante nitrogenado representa um fator complicador para a sustentabilidade dos sistemas de produção agrícola. Nesse aspecto, a adubação nitrogenada é um exemplo de desperdício energético, considerando o investimento para produzi-lo e a sua baixa recuperação pelas plantas da ordem de 50 a 60\% (Fox et al. 1974; Grove, 1979; Coelho, 1987).

A uréia é uma das fontes mais utilizadas na agricultura brasileira por apresentar elevada concentração de $\mathrm{N}$ e baixo custo por unidade de nitrogênio. Porém apresenta o sério problema de altas perdas de $\mathrm{N}$ por volatilização. Tal fenômeno tem sido considerado um dos principais motivos pelos quais a eficiência deste fertilizante culturas está abaixo da esperada (Kiehl, 1989). $\mathrm{O} \mathrm{NH}_{4} \mathrm{Cl}$ tem sido utilizado comparativamente ao $\left(\mathrm{NH}_{4}\right)_{2} \mathrm{SO}_{4}$ nos EUA como fonte de $\mathrm{N}$ em cobertura para gramíneas. Em baixas doses de aplicação, os rendimentos obtidos para ambos têm sido iguais. Em altas doses, o $\mathrm{NH}_{4} \mathrm{Cl}$ é menos eficiente que o sulfato, devido em grande parte a maior injúria nas gramíneas, quando em contato com as folhas (Tisdale, Nelson e Beaton, 1985). Geralmente o $\mathrm{NH}_{4} \mathrm{Cl}$ é considerado equivalente ao $\left(\mathrm{NH}_{4}\right)_{2} \mathrm{SO}_{4}$ ou outro fertilizante nitrogenado, quanto a sua eficiência agronômica.

\section{MATÉRIAL E MÉTODOS}

$\mathrm{O}$ experimento foi desenvolvido a campo na Fazenda Figueira localizada no município de Carambeí - PR.

$O$ experimento foi instalado no delineamento inteiramente casualizado em parcelas com 19 linhas de trigo e cevada espaçadas por $3 \mathrm{~m}$ de largura e $5 \mathrm{~m}$ de comprimento, totalizando $15 \mathrm{~m} 2$ por parcela.

As variedades de trigo utilizadas para o experimento foram a COD-104, em solo argiloso e a R1, em solo arenoso. A variedade de cevada utilizada foi a BRS 195.

A cultura do trigo foi plantada em dois tipos de solo: um argiloso e outro arenoso, e a cultura da cevada foi plantada apenas em solo arenoso. As principais características químicas destes solos, antes da aplicação dos tratamentos, estão apresentadas nas Tabelas 1, 2 e 3, enquanto que as características físicas estão apresentadas na Tabela 4 . 
Tabela 1. Características químicas de atributos de rotina.

\begin{tabular}{|c|c|c|c|c|c|c|c|c|}
\hline \multirow{2}{*}{ Ident. } & \multirow{2}{*}{$\begin{array}{l}\text { Prof. } \\
\text { cm }\end{array}$} & \multirow{2}{*}{$\begin{array}{c}\mathrm{pH} \\
\mathrm{CaCl}_{2}\end{array}$} & \multirow{2}{*}{$\begin{array}{c}\text { M.O } \\
\text { g.dm }\end{array}$} & $\mathbf{P}^{(*)}$ & $\mathbf{S}$ & $\mathbf{K}$ & $\mathrm{Ca}$ & $\mathrm{Mg}$ \\
\hline & & & & \multicolumn{2}{|c|}{ mg.dm ${ }^{-3}$} & \multicolumn{3}{|c|}{$\mathrm{mmol}_{\mathbf{c}} \cdot \mathrm{dm}^{-3}$} \\
\hline \multirow{2}{*}{ Aren. Trigo } & $0-20$ & 4,6 & 14 & 66 & 8 & 1,5 & 14 & 5 \\
\hline & $20-40$ & 4,8 & 8 & 33 & 9 & 1,5 & 13 & 4 \\
\hline \multirow{2}{*}{ Arg. Trigo } & $0-20$ & 4,7 & 34 & 29 & 17 & 2,7 & 37 & 18 \\
\hline & $20-40$ & 4,8 & 27 & 6 & 17 & 1,0 & 32 & 15 \\
\hline \multirow{2}{*}{ Aren. Cev. } & $0-20$ & 4,9 & 19 & 48 & 14 & 2,0 & 26 & 13 \\
\hline & $20-40$ & 5,0 & 13 & 14 & 12 & 1,6 & 25 & 2 \\
\hline
\end{tabular}

Tabela 2. Características químicas de atributos de rotina.

\begin{tabular}{cccccccc}
\hline \multirow{2}{*}{ Ident. } & Prof. & H+Al & Al & SB & T & V & m \\
\cline { 2 - 8 } & $\mathbf{c m}$ & \multicolumn{3}{c}{$-----\mathbf{m m o l}_{\mathbf{c} . \mathbf{d m}^{-3}-----}$} & \multicolumn{2}{c}{} \\
\hline \multirow{2}{*}{ Aren. Trigo } & $0-20$ & 34 & 3 & 21 & 55 & 38 & 13 \\
& $20-40$ & 20 & 1 & 19 & 39 & 48 & 5 \\
\hline \multirow{2}{*}{ Arg. Trigo } & $0-20$ & 64 & 3 & 58 & 122 & 47 & 5 \\
& $20-40$ & 52 & 3 & 48 & 100 & 48 & 6 \\
\hline \multirow{2}{*}{ Aren. Cev } & $0-20$ & 42 & 2 & 41 & 83 & 49 & 5 \\
& $20-40$ & 34 & 2 & 29 & 63 & 46 & 7 \\
\hline
\end{tabular}

Tabela 3. Teores de micronutrientes da área experimental

\begin{tabular}{|c|c|c|c|c|c|c|}
\hline Identif. & Prof. & $\mathrm{B}\left({ }^{*}\right)$ & $\mathrm{Cu}(* *)$ & $\mathrm{Fe}\left({ }^{* *}\right)$ & $\mathbf{M n}(* *)$ & $\operatorname{Zn}\left({ }^{* *}\right)$ \\
\hline & cm & & & mg.dm- & & \\
\hline \multirow{2}{*}{ Aren. Trigo } & $0-20$ & 0,29 & 0,9 & 80 & 3,9 & 2,3 \\
\hline & $20-40$ & 0,21 & 0,2 & 32 & 1,5 & 0,9 \\
\hline \multirow{2}{*}{ Arg. Trigo } & $0-20$ & 0,40 & 1,5 & 42 & 5,0 & 1,9 \\
\hline & $20-40$ & 0,32 & 1,2 & 26 & 2,2 & 0,8 \\
\hline \multirow{2}{*}{ Aren. Cevada } & $0-20$ & 0,29 & 1,0 & 46 & 5,9 & 1,7 \\
\hline & $20-40$ & 0,29 & 0,8 & 35 & 2,7 & 0,7 \\
\hline
\end{tabular}

(*) Água Quente (**) DTPA 
Tabela 4. Resultado da análise granulométrica do solo.

\begin{tabular}{|c|c|c|c|c|c|c|}
\hline \multirow{3}{*}{ Ident. } & \multirow{3}{*}{$\begin{array}{l}\text { Prof. } \\
\mathrm{cm}\end{array}$} & Argila & \multirow{3}{*}{$\begin{array}{l}\text { Silte } \\
0,053-0,002\end{array}$} & \multirow{2}{*}{$\begin{array}{l}\text { Areia } \\
\text { total }\end{array}$} & \multirow{2}{*}{$\begin{array}{l}\text { Areia grossa } \\
2,00-0,210\end{array}$} & \multirow{2}{*}{$\begin{array}{l}\text { Areia fina } \\
0,210-0,053\end{array}$} \\
\hline & & $<\quad 0,002$ & & & & \\
\hline & & \multicolumn{4}{|c|}{----g.kg ${ }^{-1}-\cdots--$} & \\
\hline Aren. & $0-20$ & 140 & 50 & 810 & 150 & 660 \\
\hline Trigo & $20-40$ & 131 & 59 & 810 & 130 & 680 \\
\hline Arg. & $0-20$ & 536 & 254 & 210 & 60 & 150 \\
\hline Trigo & $20-40$ & 548 & 272 & 180 & 40 & 140 \\
\hline Aren. & $0-20$ & 161 & 89 & 750 & 140 & 610 \\
\hline Cevada & $20-40$ & 161 & 109 & 730 & 120 & 610 \\
\hline
\end{tabular}

O experimento foi realizado com dois cereais: trigo e cevada. A cultura do trigo foi instalada em solos arenoso e argiloso, havendo para cada tipo de solo um tratamento controle $(0 \mathrm{Kg} / \mathrm{ha}$ de $\mathrm{N})$ e mais três tratamentos com as doses; 20,40 e 80 $\mathrm{Kg} / \mathrm{ha}$ de $\mathrm{N}$ dos dois fertilizantes testados (uréia e cloreto de amônio), totalizando assim 7 tratamentos com 4 repetições para ambos os solos, ou seja, 56 parcelas . A cultura da cevada foi instalada apenas em solo arenoso, sendo que neste também houve um tratamento controle e mais três tratamentos com as mesmas doses e fertilizantes adotados para a cultura do trigo, totalizando 7 tratamentos com 4 repetições, ou seja, 28 parcelas. Desta forma o experimento contou com um total de 84 parcelas (Tabela 5).

Tabela 5. Tratamentos aplicados.

\begin{tabular}{ccc}
\hline Tratamento & Fontes de N & $\begin{array}{c}\text { Dose de N } \\
\mathrm{kg}^{-1} \mathrm{ha}^{-1}\end{array}$ \\
\hline 1 & Controle & 0 \\
2 & Cloreto de amônio & 20 \\
3 & Cloreto de amônio & 40 \\
4 & Cloreto de amônio & 80 \\
5 & Uréia & 20 \\
6 & Uréia & 40 \\
7 & Uréia & 80 \\
\hline
\end{tabular}

* Análises realizadas nos laboratórios do Departamento de Solos e Nutrição de Plantas - ESALQ/USP 
A adubação de semeadura com $\mathrm{N}, \mathrm{P}$, $\mathrm{K}$ foi realizada de acordo com a análise de solo e exigências das culturas, aplicando-se $300 \mathrm{Kg} / \mathrm{ha}$ da formulação 14-34-00 na cultura do trigo. Foram aplicados $160 \mathrm{Kg}$ de $\mathrm{KCl}$ (96 kg/ha de K2O) em cobertura na cultura do trigo em ambos os solos (argiloso e arenoso) logo após a emergência das plantas, já a cultura da cevada não recebeu potássio em cobertura.
As fontes de nitrogênio (cloreto de amônio e uréia) foram aplicadas em cobertura nas doses de $0,20,40$ e $80 \mathrm{Kg}$ de $\mathrm{N}$ por hectare para ambas as culturas, por volta de 30 dias após a emergência.

As garantias dos fertilizantes, bem como as análises químicas dos mesmos estão apresentadas na Tabela 6 .

Tabela 6. Garantias e análise química das fontes de nitrogênio.

\begin{tabular}{ccc}
\hline Garantia & Uréia (\%) & Cloreto de Amônio (\%) \\
$\mathrm{N}$ & 45 & 26 \\
Análise* & & \\
$\mathrm{N}$ (total) & 45,50 & 25,98 \\
$\mathrm{~N}$ (amoniacal) & 0,32 & 25,77 \\
$\mathrm{~N}$ (nítrico) & 0,01 & - \\
Cloro & - & 64,68
\end{tabular}

* Analises realizadas no laboratório do Departamento de Ciência do Solo

A coleta das folhas para análise dos tecidos foliares foi feita retirando-se a folha bandeira e as duas logo abaixo desta. As plantas se encontravam no final do florescimento, já no início do enchimento dos grãos. Foram amostradas quinze plantas por parcela, sendo estas coletadas nas linhas centrais. Foram retirados amostras de folhas para avaliação do estado nutricional pela técnica da diagnose foliar, cujos resultados estão em anexo. Cada parcela foi colhida para a estimativa de produção de grãos e para a quantificação do teor de proteína bruta pelo método micro-Kjeldahl.

\section{RESULTADOS E DISCUSSÃO}

A cultura de trigo conduzida em solo arenoso não houve diferença estatística entre os tratamentos no teor de $\mathrm{N}$ na folha (Tabela 7). Já no solo argiloso os tratamentos T3 (cloreto de amônio na dose de $40 \mathrm{~kg} / \mathrm{ha}$ de $\mathrm{N}$ ) e T7 (uréia na dose de $80 \mathrm{~kg} / \mathrm{ha}$ de $\mathrm{N}$ ) apresentaram maiores teores, porém não se diferenciando estatisticamente dos tratamentos T4 (cloreto de amônio na dose de $80 \mathrm{~kg} / \mathrm{ha}$ de N) e T6 (uréia na dose de $40 \mathrm{~kg} /$ ha de N) (Tabela 7).

Para a cultura da cevada conduzida em solo arenoso, observou-se que o tratamento T4 apresentou maior teor, no entanto não se diferenciaram estatisticamente dos tratamentos T2 (cloreto na dose de $20 \mathrm{~kg} / \mathrm{ha}$ de N), T5 (uréia na dose de $20 \mathrm{~kg} / \mathrm{ha}$ de N), T6 e T7 (Tabela 7). 
Tabela 7. Teor de nitrogênio na folha de todos os tratamentos e resumo da análise estatística.

\begin{tabular}{cccc}
\hline \multirow{2}{*}{ Tratamentos } & \multicolumn{3}{c}{$\begin{array}{c}\text { Teor de } \mathrm{N} \\
\text { g.kg }\end{array}$} \\
\cline { 2 - 4 } & Trigo solo arenoso & Trigo solo argiloso & Cevada solo arenoso \\
\hline 1 & $20,63 \mathrm{a}$ & $23,50 \mathrm{c}$ & $23,47 \mathrm{c}$ \\
2 & $21,23 \mathrm{a}$ & $24,87 \mathrm{bc}$ & $25,63 \mathrm{abc}$ \\
3 & $21,10 \mathrm{a}$ & $28,83 \mathrm{a}$ & $24,50 \mathrm{bc}$ \\
4 & $20,00 \mathrm{a}$ & $27,85 \mathrm{ab}$ & $28,83 \mathrm{a}$ \\
5 & $20,07 \mathrm{a}$ & $23,53 \mathrm{c}$ & $26,13 \mathrm{abc}$ \\
6 & $20,93 \mathrm{a}$ & $28,03 \mathrm{ab}$ & $27,70 \mathrm{ab}$ \\
7 & $22,50 \mathrm{a}$ & $30,23 \mathrm{a}$ & $28,13 \mathrm{ab}$ \\
\hline CV $(\%)$ & 7,5 & 5,26 & 6,05 \\
DMS & 3,67 & 3,28 & 3,73 \\
\hline
\end{tabular}

Para cultura de trigo conduzido em solo arenoso, os tratamentos apresentaram diferença estatística na produção de grãos (Tabela 7). O tratamento T4 (cloreto de amônio na dose de $80 \mathrm{~kg} /$ ha de $\mathrm{N}$ ) foi o que apresentou maior produção em relação aos demais tratamentos, no entanto não se diferenciou estatisticamente dos tratamentos T3 e T7, (cloreto de amônio na dose de $40 \mathrm{~kg} / \mathrm{ha}$ de $\mathrm{N}$ e uréia na dose de $80 \mathrm{~kg} / \mathrm{ha}$, respectivamente) (Tabela 7). É possivel observar também que esses tratamentos são considerados estatisticamente superiores aos demais tratamentos.
Na área em que a cultura do trigo foi conduzida em solo argiloso, observa-se que o tratamento 6 (uréia na dose de $40 \mathrm{~kg} / \mathrm{ha}$ de $\mathrm{N})$, embora tenha apresentado maior produção, esta não pode ser considerada estatisticamente diferente das produções obtidas pelos tratamentos T2, T3, T4 e T7.

Na área de cevada conduzida em solo arenoso, o tratamento $\mathrm{T} 4$ resultou em maior produção de grãos, porém não apresentou diferença estatística dos tratamentos T2, T3 e T7

O efeito das fontes estudadas são apresentados nas figuras $1 ; 2$ e 3 
Tabela 8. Produção de grãos de todos os tratamentos e resumo da análise estatística.

\begin{tabular}{cccc}
\hline \multirow{2}{*}{ Tratamentos } & \multicolumn{3}{c}{$\begin{array}{c}\text { Teor de N } \\
\mathrm{g}^{-\mathrm{kg}^{-1}}\end{array}$} \\
\cline { 2 - 4 } & Trigo solo arenoso & Trigo solo argiloso & Cevada solo arenoso \\
\hline 1 & $1,32 \mathrm{c}$ & $1,97 \mathrm{~d}$ \\
2 & $1,89 \mathrm{bc}$ & $2,44 \mathrm{c}$ & $3,18 \mathrm{ab}$ \\
3 & $2,17 \mathrm{ab}$ & $3,31 \mathrm{abc}$ & $3,04 \mathrm{abc}$ \\
4 & $2,70 \mathrm{a}$ & $3,36 \mathrm{ab}$ & $3,42 \mathrm{a}$ \\
5 & $1,51 \mathrm{bc}$ & $2,73 \mathrm{bc}$ & $2,76 \mathrm{bc}$ \\
6 & $1,82 \mathrm{bc}$ & $3,51 \mathrm{a}$ & $2,58 \mathrm{c}$ \\
7 & $2,10 \mathrm{ab}$ & $3,13 \mathrm{abc}$ & $3,04 \mathrm{abc}$ \\
\hline CV $(\%)$ & 15,51 & 10,29 & 8,92 \\
DMS & 0,70 & 0,73 & 0,59 \\
\hline
\end{tabular}

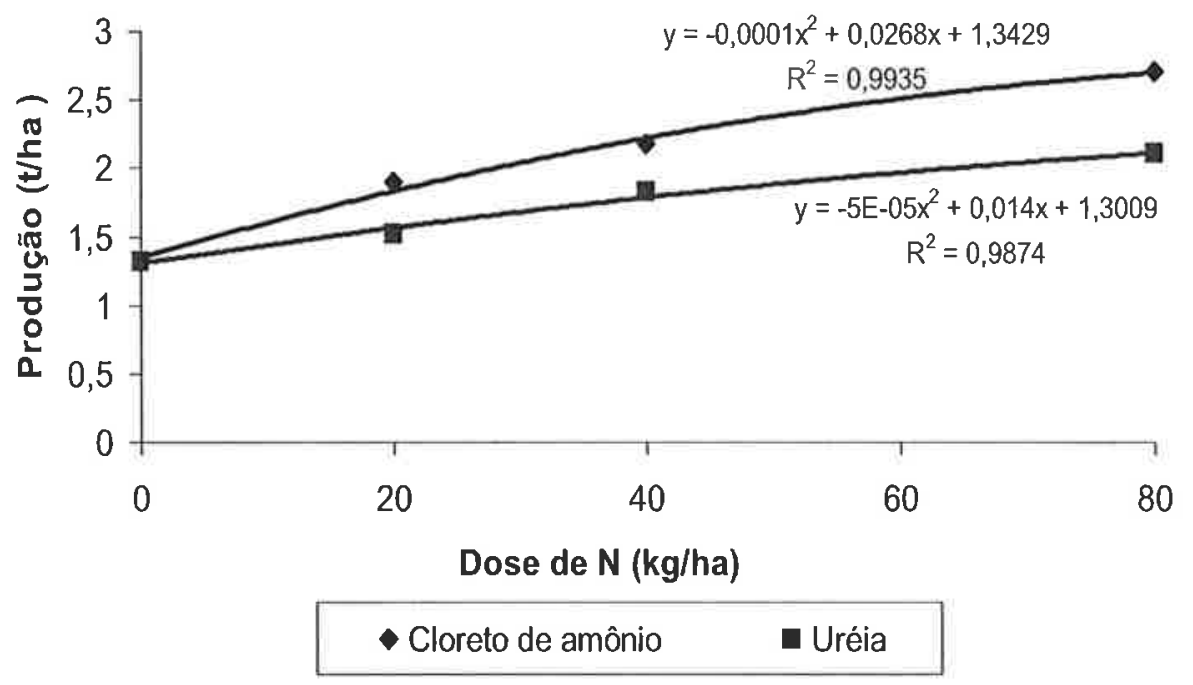

Figura 1. Produção de trigo em solo arenoso 


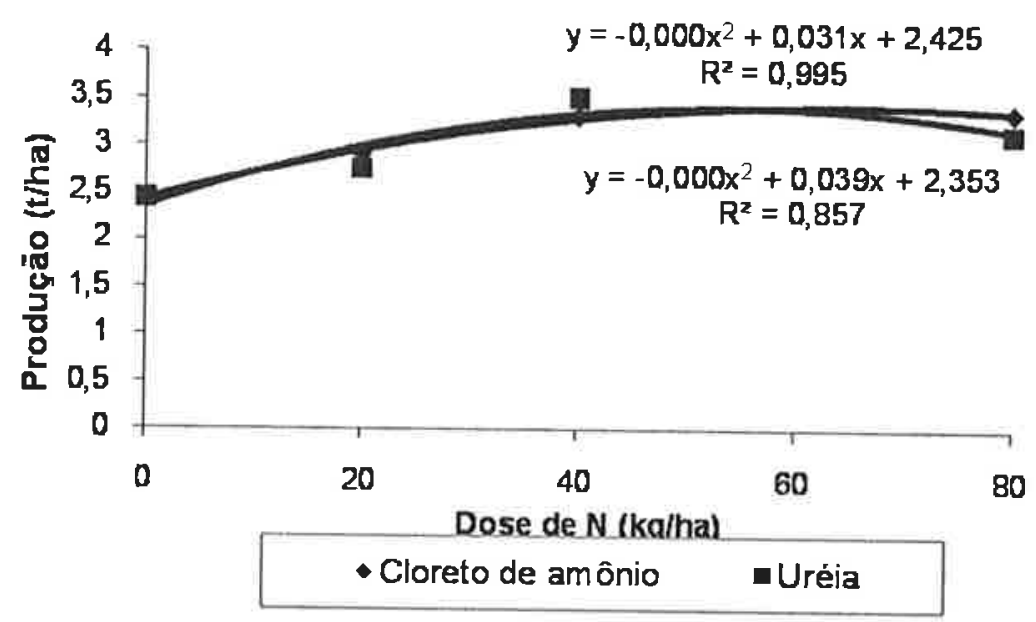

Figura 2. Produção de trigo em solo argiloso

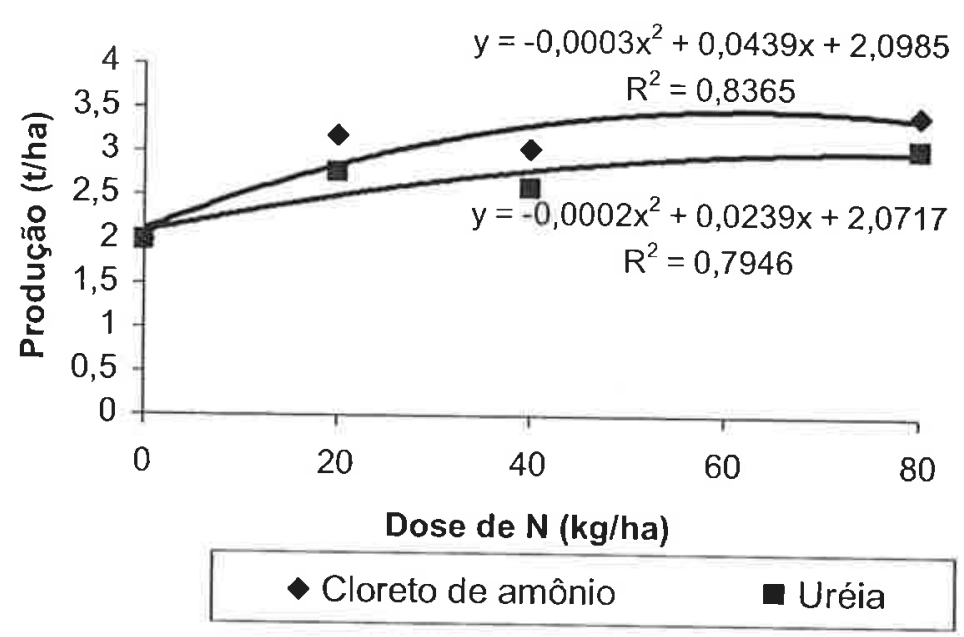

Figura 3. Produção de cevada em solo arenoso

$\mathrm{Na}$ cultura do trigo cultivado em solo arenoso(Tabela 7), o tratamento $\mathrm{T} 4$ (cloreto de amônio na dose de $80 \mathrm{~kg} / \mathrm{ha}$ ) apresentou maior teor de proteína bruta na matéria seca dos grãos, não diferindo estatisticamente apenas do tratamento T7 (uréia na dose de $80 \mathrm{~kg} / \mathrm{ha}$ ).

Na cultura do trigo cultivada em solo argiloso os tratamentos T4 e T7 foram os que apresentaram maior teor de proteína bruta, diferindo estatisticamente dos demais 
tratamentos.Também se observa que para a cultura da cevada cultivada em solo arenoso, o tratamento T7 apresentou tendência de maior teor de proteína bruta, porém estatisticamente só diferiu do tratamento $\mathrm{T} 1$ (controle).
Nos gráficos de 4 a 6 , são apresentados o efeito dos tratamentos no teor de proteína bruta, onde observa-se aumento desse parâmetro pelo aumento da dose de $\mathrm{N}$, nas duas fontes.

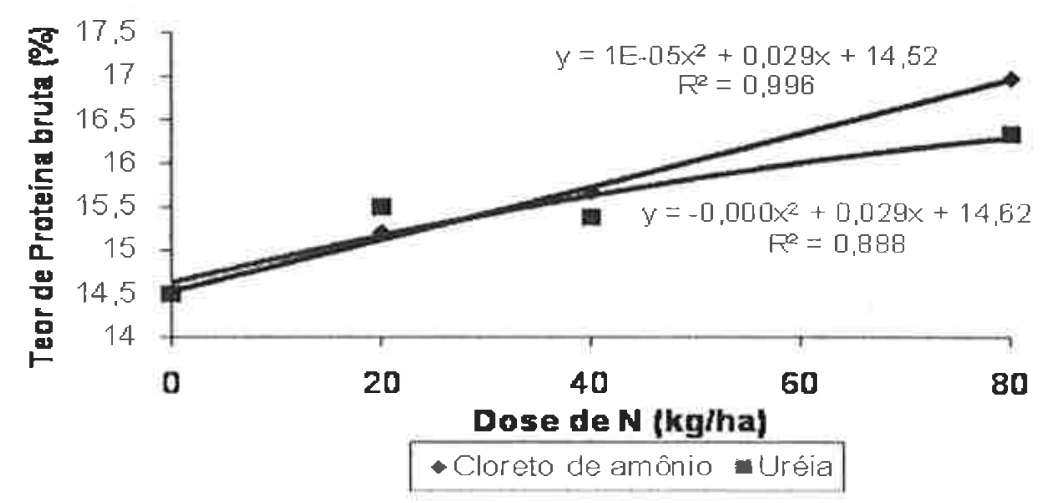

Figura 4. Teor de Proteína Bruta - Trigo em solo arenoso

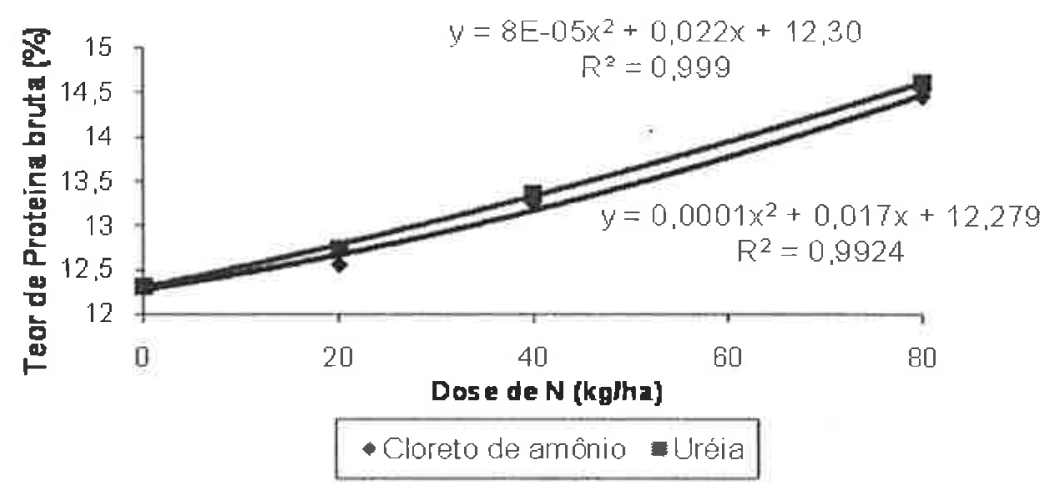

Figura 5. Teor de Proteína bruta - Trigo em solo argiloso 


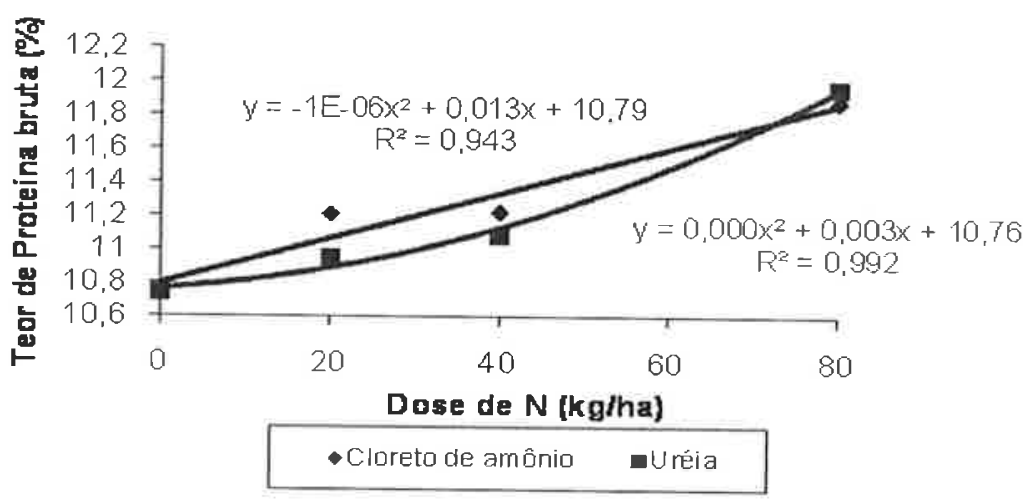

Figura 6. Teor de Proteína bruta - Cevada em solo arenoso

\section{CONCLUSÕES}

As culturas de trigo e cevada que recebem o tratamento com Cloreto de amônio apresentam teores adequados de $\mathrm{N}$ na folha, mostrando ser, esta fonte, eficiente quanto ao fornecimento deste nutriente. As culturas de trigo em solo argiloso e cevada em solo arenoso apresentam aumentos significativos nos teores de $\mathrm{N}$ foliar pela aplicação de $\mathrm{N}$ independentes das fontes utilizadas;

A produção de grãos tem aumentos significativos pela aplicação de $\mathrm{N}$ em cobertura independentemente da fonte utilizada, revelando ser o Cloreto de amônio, fonte alternativa com potencial para fornecimento de N;

Quanto ao teor de Proteína bruta ocorre aumento significativo pelo uso de $\mathrm{N}$ independente da fonte testada;

O Cloreto de amônio e a uréia promovem aumentos significativos nos teores de $\mathrm{N}$ foliar, Proteína bruta dos grãos e Produção de grãos, aumentos estes que não apresentam diferenças entre as fontes utilizadas

\section{REFERÊNCIAS BIBLIOGRAFICAS}

FOX, R. H.; TALLEYRAND, H. \& BOULDIN, D. R. Nitrogen fertilization of corn and sorgum in Oxisol e Ultisols, in Puerto Rico. Agronomy Journal, Madison, 66 (3): 534-40; $1974 .$.

KIEHL, J. C. Distribuição e Retenção da Amônia No Solo Apos Aplicação de Uréia. Revista Brasileira de Ciência do Solo, v. 13, n. 1, p. 75-80, 1989.

TISDALE, S.L.; NELSON, W.L.; BEATON, J.D. Soil fertility and fertilizers. 4 ed., Macmillan Publishing company, New York, 1985. 754p

VITTI, G. C.; FAVARIN, J.L.; RESENDE. L. O.; TREVISAN, W. Manejo do Nitrogênio em diversos sistemas de produção agrícola. SERRANA/GAPE. Piracicaba, 1999. 38p.

VITTI, G.C.; MALAVOLTA, E; COUTINHO, E.L.M. Uso eficiente de fertilizantes nitrogenados e portadores de enxofre. In: SPINOZA, W. \& OLIVEIRA, A.J. de. Anais do Simpósio sobre Fertilizantes na Agricultura Brasileira. EMBRAPA-DEP. 1984. p. 205-253. 
VITTI.G.C.; HEIRINCHIS R.; Formas tradicionais e alternativas de obtenção e utilização do nitrogênio e do enxofre: Uma visão holística. In: Anais do
Simposio de Nitrogenio e Enxofre na Agricultura Brasileira 2007. Cap.4. $109-157 \mathrm{p}$. 